\title{
Skin Cancer and Its Correlates: A Study of Knowledge and Preventive Behavior in Riyadh
}

\author{
Fahad Alamri ${ }^{1}$, Mohammed Y. Saeedi ${ }^{1}$, Muslet Alharbi ${ }^{2}$, Arwa M. Ali ${ }^{3,4}$, AhmedK. Ibrahim ${ }^{5} \&$ Kassim A. \\ Kassim $^{1}$ \\ ${ }^{1}$ Deputy Ministry for Public Health, Assistant Deputy for Primary Health Care, Ministry of Health, Riyadh, \\ Saudi Arabia \\ ${ }^{2}$ Community Medicine Department, King Saud University, Riyadh, Saudi Arabia \\ ${ }^{3}$ Medical Oncology Department, King Khalid University Hospitals, King Saud University, Riyadh, Saudi Arabia \\ ${ }^{4}$ Medical Oncology Department, South Egypt Cancer Institute, Assiut University, Asyut, Egypt \\ ${ }^{5}$ Public Health \& Community Medicine department, Faculty of Medicine, Assiut University, Asyut, Egypt \\ Correspondence: Fahad Alamri, Deputy Ministry for Public Health, Assistant Deputy for Primary Health Care, \\ Ministry of Health, Riyadh, Saudi Arabia. E-mail: fahadamri@yahoo.com
}

Received: October 20, 2015 Accepted: November 23, 2015 Online Published: December 8, 2015

doi:10.5539/cco.v5n1p11 URL: http://dx.doi.org/10.5539/cco.v5n1p11

\begin{abstract}
Background: Worldwide, the incidence of skin cancer has increased due to increased UV exposure to solar and artificial sources. In Saudi Arabia, skin cancer ranked the $9^{\text {th }}$ most common cancer for both sexes. However, it is considered to be a preventable disease. WHO has proposed several preventive methods to avoid the damaging effects of excessive exposure to UV rays including; social education and adopting positive behavioral changes. The present study aimed to evaluate the level of knowledge, attitudes and behaviors of people in Riyadh city towards skin cancer. Results: The mean respondent's age was 35 years (12-65 years). Females represented about two-thirds of the 341 respondent. A statistically significant associations were detected between awareness about skin cancer with the age $(B e t a=0.03, p=0.047)$, educational level $($ Beta $=0.63, p=0.042)$ and skin color (Beta $=-2.14, p<0.001)$ being significant predictors for disease. Conclusions: To our knowledge, this was the first study to assess the level of knowledge, attitudes, and practices regarding skin cancer in Saudi Arabia. Despite the limitations, the present study's findings suggested that Saudis lack the sufficient knowledge to understand and assess the importance of skin cancer risk. In addition, the level of knowledge, attitude and behaviors are influenced by several factors as age, education level and skin color.
\end{abstract}

Keywords: skin cancer, knowledge, attitude and sun exposure

\section{Introduction}

It has been proposed that skin cancer has increased progressively during the past four decades (Rigel, 2004). Melanoma (MSC) and non-melanoma skin cancer (NMSC) are now one of the most common types of cancer in white populations. Both tumor entities showed an increasing incidence worldwide, but a stable or decreasing mortality rate (Leiter, Eigentler, \& Garbe, 2014).

Being the most rapidly increasing cancer in white populations, cutaneous melanoma has up to 5 -fold increase in its incidence rate over the last three decades (Xiang, Lucas, Hales, \& Neale, 2014). The frequency of its occurrence was closely associated with the constitutive color of the skin and depends on the geographical zone. The highest incidence rates have been reported in Queensland, Australia with 56 new cases per year per 100,000 population for men and 43 for women (Leiter \& Garbe, 2008).

The American Cancer Society (ACS) estimated 76,690 new cases of melanoma in 2013 with more than 9,000 deaths attributed to this type of cancer during the same year (American Cancer Society, 2013). Mortality rates of melanoma showed stabilization in the USA, Australia and Europe during the last decade (Leiter \& Garbe, 2008; Lucas, 2006).

According to the most recent report of Saudi Cancer Registry (SCR), NMSC ranked the $9^{\text {th }}$ most common cancer for both sexes, accounting for $3.2 \%$ of all newly diagnosed cancer cases $(52.7 \%$ males and $47.3 \%$ females with a 
male to female ratio of 111:100) in 2010 (Haya, 2014). The overall Age-specific ratio (ASR) was 3/100,000 (3.1 and 2.8/100,000 for males and females, consequently) (Haya, 2014).

Several factors have been identified as skin cancer correlates such as fair skin, blue, green or hazel eyes, light-colored hair, tendency to burn rather than suntan, history of severe sunburns, exposure to UV rays, many moles or freckles and a family history of skin cancer (WHO, 2015). Skin cancers are less common in dark-skinned people, the low incidence is primarily a result of photo protection provided by increased epidermal melanin, which filters twice as much ultraviolet (UV) radiation as in the epidermis of Caucasians (Bradford, 2009). However, dark-skinned people tend to have poor skin cancer prognosis because of the late diagnosed (Nyiri, 2005).

For the major types of skin cancer, exposure to UV rays is considered to be the most common modifiable risk factor. Moreover, it could be resulted from excessive outdoor activities, changes in clothing style, increased longevity and ozone depletion (Leiter \& Garbe, 2008). Additionally, dose-dependent increase in the risk of squamous cell carcinoma (SCC) was found to be associated with exposure to Psoralen and UVA irradiation (Leiter \& Garbe, 2008). Nearly all skin cancers are preventable, as the majority of them were attributed to sun exposure (Koh \& Geller, 2004). Therefore, WHO has proposed several preventive methods to avoid the damaging effects of excessive exposure to UV rays including; social education and adopting positive behavioral changes (WHO, 2015).

Publications and surveys about the knowledge, attitude and practice related to skin cancer and sun protection have been conducted in many countries. The main objectives of these studies were; obtaining locally relevant information about primary and secondary prevention, identifying populations at high risk, and evaluating the running educational programs (Aquilina, Gauci, Ellul, \& Scerri, 2004; Cokkinides et al., 2006; Geller et al., 2005; Harrison, Saunders, \& Nowak, 2007; Jones, Oh, Corkery, Hanley, \& Egan, 2007). Unfortunately, skin cancer publications in the KSA are scarce which represents challenge for the current work.

The aim of the present study was to evaluate the levels of knowledge, attitudes and behaviors of people in Riyadh city, KSA towards the skin cancer.

\section{Patients and Methods}

Study design: Cross-sectional study design was applied.

Study setting: Randomly selected shopping malls in Riyadh City, KSA.

Sample size calculation: Sample size was calculated using the formula presented by the WHO for descriptive studies: $\boldsymbol{N = Z ^ { 2 } * p ( \mathbf { 1 0 0 } - \boldsymbol { p } ) / \boldsymbol { e } ^ { 2 }}$ where; "N" is the required sample size, "Z" is a value corresponding to the significance level, "P" is the expected percentage of people with adequate knowledge and attitude and "e" is the level of precision. Based upon literature review for previous studies; it was expected that $22 \%$ of Saudis would have adequate knowledge and hence the minimum required sample (according to the above formula) was 264 and this was increased to include 300 participants.

Sampling technique: From each of the five regions of Riyadh city (East, west, central, north and south), one mall was selected randomly. Eligibility criteria for participation were: both genders, age $\geq 18$ years and willing to participate (after the consent process).

Data collection methods: A modified version of Avaya's tool was used for the current study (7). It is composed of four sections: demographics, knowledge, attitudes and practice. Self-administered questionnaires were used for data collection. It included information on demographic characteristics, socio-economic status, skin type, knowledge about solar exposure, knowledge of cancer, knowledge of sun prevention, attitudes toward sun tanning, use of sun beds, and practices in sun protection. The level of awareness was calculated as the sum of the correct answers ranging from 0 to 20 points.

Pilot study: A pilot study was conducted on a sample of 20 people. This pilot was used to test the logistics of data collection, clarity of the data collection tool (for modification) and to estimate the proper time required for data collection.

Data analysis plan: SPSS v21 software was used for data entry, management and analysis. Descriptive statistics: means, standard deviations and percentages along with their $95 \%$ Confidence Interval (CI) were calculated. The entire sample was used for the final analysis, as the missing data did not exceed $10 \%$ for any of the questions. Test of significances: t-test and ANOVA was calculated to test the mean differences in continuous variables between groups, while linear regression analysis (univariate and multivariate) was used for the prediction of the most important factors associated with the level of awareness. A significant $\mathrm{p}$ value was considered when it is $\leq$ 
0.05 .

Ethical considerations: The purpose of the study, the rights of the participant, to withdraw at any time without any obligation towards the study team and to contact the study team for any query were fully detailed in the informed consent. Participant's anonymity was assured by assigning each participant a code number for the purpose of analysis only. No incentives or rewards were given to participants. Institutional review board (IRB) approval was obtained for this study prior to study execution.

\section{Results}

The study was carried out in the five regions of Riyadh city, KSA. A total of 341 participants completed the study questionnaire and were included in the final analysis. The mean respondent's age was 35 years (12-65 years) with females representing about two-thirds of the samples (63\%). Furthermore, the majority of the sample was Saudi citizens (90\%). Regarding the level of education; nearly all participants can read and write $(90 \%)$ with about half of them had university education or above (Table 1). Moreover, married respondents represented slightly more than half of the cohort (55\%). Almost equal proportions of participants were employed and unemployed. For the monthly family income, about $60 \%$ of the respondents earned between 3,000 and 20,000 SR per month. As Saudi Arabia has a desert-climate, about two-thirds of the study cohort had darker colored skin (Table 1).

Table 1. Demographic and other characteristics of the study participants

\begin{tabular}{|c|c|c|}
\hline Variable & Category & $N=341$ \\
\hline Age $($ Mean \pm SD) & \multicolumn{2}{|c|}{$34.6 \pm 12.1$} \\
\hline \multirow[t]{2}{*}{ Sex } & - Male & $126(37 \%)$ \\
\hline & - Female & $215(63 \%)$ \\
\hline \multirow[t]{2}{*}{ Nationality } & - $\quad$ Saudi & $307(90 \%)$ \\
\hline & - Non-Saudi & $34(10 \%)$ \\
\hline \multirow[t]{6}{*}{ Educational Level } & - Illiterate & $34(10 \%)$ \\
\hline & - Primary & $31(9.1 \%)$ \\
\hline & - Middle & $43(12.6 \%)$ \\
\hline & - Secondary & $87(25.5 \%)$ \\
\hline & - University & $133(39 \%)$ \\
\hline & - $\quad$ Post-grads & $13(3.8 \%)$ \\
\hline \multirow[t]{4}{*}{ Marital Status } & - $\quad$ Married & $189(55.4 \%)$ \\
\hline & - Single & $114(33.4 \%)$ \\
\hline & - Divorced & $18(5.3 \%)$ \\
\hline & - Widow(er) & $20(5.9 \%)$ \\
\hline \multirow[t]{2}{*}{ Occupational Status } & - Employed & $163(47.8 \%)$ \\
\hline & - Unemployed & $178(52.2 \%)$ \\
\hline \multirow[t]{4}{*}{ Family Income/month } & - $\quad<3,000$ & $122(35.8 \%)$ \\
\hline & - $\quad 3,000-10,000$ & $119(34.9 \%)$ \\
\hline & - $10,000-20,000$ & $80(23.4 \%)$ \\
\hline & - $\quad>20,000$ & $20(5.9 \%)$ \\
\hline \multirow[t]{2}{*}{ Skin Colour } & - $\quad$ Fair & $98(28.7 \%)$ \\
\hline & - Dark & $243(71.3 \%)$ \\
\hline
\end{tabular}


Table 2 showed the distribution of awareness scores among the studied sample. The total score showed normal distribution parameters i.e. mean \pm SD $(9.8 \pm 3.5)$ and median 10 . Likewise, the scores showed nearly normally distributed pattern on the depicted histogram as shown in Figure 1.

Table 2. Descriptive data of the lab findings of the sample

\begin{tabular}{lccc}
\hline Variable & Mean \pm SD & Median & Range \\
\hline Knowledge Score & $7.9 \pm 2.9$ & 8.0 & $0.0-17.0$ \\
Attitude Score & $1.9 \pm 1.0$ & 2.0 & $0.0-5.0$ \\
Total Awareness Score & $9.8 \pm 3.5$ & 10.0 & $0.0-20.0$ \\
\hline
\end{tabular}

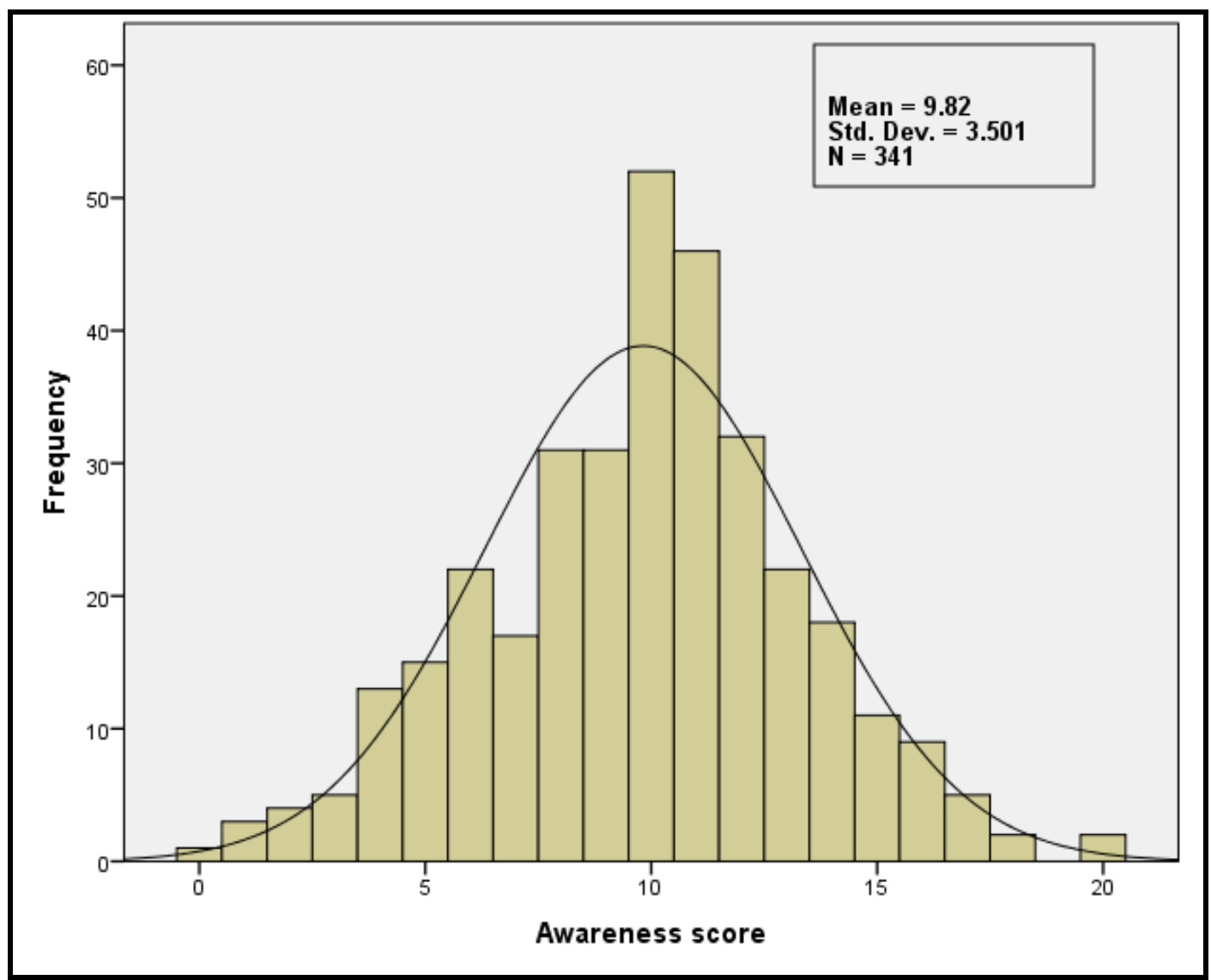

Figure 1. Distribution of awareness scores among the studied cohort

The percentage of correct answers regarding the level of awareness about skin cancer and the related risk behaviors were illustrated in Table 3. Respecting the level of knowledge, those with correct answers ranged between $17 \%$ and $84 \%$. Similarly, the percentage of the correct answers for attitude ranged from $25 \%$ to $62 \%$.

Moreover, participants had higher levels of general knowledge regarding the disease (e.g. the majority answered correctly when asked if ultraviolet rays from the sun cause suntan?), while, there was shortage in the specific knowledge about the disease and its correlates (e.g. less than one-fifth gave correct answer to the question "Sun exposure can cause skin cancer").

In regard to the level of attitude; there was general deficiency as indicated by the participant's' response to the attitude questions i.e. for the probe "I'm concerned; exposure to the sun/UV may give me skin cancer", only 33\% answered correctly (Table 3). 
Table 3. Knowledge and attitude about skin cancer among the studied sample

\begin{tabular}{|c|c|}
\hline Probe & Correct answer n (\%) \\
\hline \multicolumn{2}{|l|}{ - The Level of Knowledge } \\
\hline 1. Ultraviolet rays from the sun cause suntan & $253(74.2 \%)$ \\
\hline 2. Too much sun exposure can cause freckles & $199(58.4 \%)$ \\
\hline 3. Too much sun exposure can cause wrinkles on the skin & $159(46.6 \%)$ \\
\hline 4. Sun exposure can cause skin cancer & $57(16.7 \%)$ \\
\hline 5. The sun is more harmful to dark skin than to fair skin & $209(61.3 \%)$ \\
\hline 6. The sun is more harmful to fair skin than to dark skin & $157(46.0 \%)$ \\
\hline 7. The sun is harmful for your skin only when you get sunburn & $77(22.6 \%)$ \\
\hline 8. A suntan is a sign of being healthy & $287(84.2 \%)$ \\
\hline 9. The sun is strongest and most harmful between $11.00 \mathrm{am} \& 4.00 \mathrm{pm}$ & $262(76.8 \%)$ \\
\hline 10. You cannot get too much sun on a cloudy day & $178(52.2 \%)$ \\
\hline 11. Sunscreen can protect from ultraviolet radiation & $165(48.4 \%)$ \\
\hline $\begin{array}{l}\text { 12. Sunscreen with sun protection factor (SPF) less than } 15 \text { minutes is not } \\
\text { enough toprotect you }\end{array}$ & $189(55.4 \%)$ \\
\hline 13. One application of sunscreen protects your skin for at least 4 hours & $74(21.7 \%)$ \\
\hline 14. There is nothing I can do to prevent skin cancer & $66(19.4 \%)$ \\
\hline 15. Melanoma is the most dangerous type of skin cancer & $116(34.0 \%)$ \\
\hline $\begin{array}{l}\text { 16. Many severe sunburns in childhood increase chance of getting skin } \\
\text { cancerlater on }\end{array}$ & $107(31.4 \%)$ \\
\hline $\begin{array}{l}\text { 17. The number of moles a person has is an important risk factor for } \\
\text { developingmelanoma }\end{array}$ & $145(42.5 \%)$ \\
\hline \multicolumn{2}{|l|}{ - The Level of Attitude } \\
\hline 1. My skin will age more quickly if I spend time in thesun & $147(43.1 \%)$ \\
\hline 2. I'm concerned, exposure to the sun/UV may give me skin cancer & $112(32.8 \%)$ \\
\hline 3. A suntan makes me look attractive & $85(24.9 \%)$ \\
\hline 4. A suntan makes me look healthier & $212(62.2 \%)$ \\
\hline 5. Sun beds are a safe way to tan & $93(27.3 \%)$ \\
\hline
\end{tabular}

Table 4 demonstrated the association between the level of awareness about skin cancer and the main socio-demographic determinants of the disease among the study group. It was found that marital status and skin color of the respondents were significantly associated with the awareness level. In other words, married participants were less knowledgeable about the disease while those with dark skin coloration had higher mean scores on the awareness scale. These relationships were statistically significant $(\mathrm{P}<0.05)$.

Moreover, educational level and monthly family income of the respondents showed borderline significant association with the level of awareness ( $\mathrm{p}=0.063$ and 0.059 , respectively). Videlicet, those with higher education reported higher mean scores on the awareness scale followed by those with lower education then those who were illiterates. Also, it was found that the higher the monthly income of the family, the higher the mean awareness level scores (Table 4). 
Table 4. Differences in Awareness mean scores for different Socio-demographic and other characteristics among the studied cohort

\begin{tabular}{|c|c|c|c|}
\hline Variable & Category & $\begin{array}{c}\text { Awareness Score } \\
(\text { mean } \pm \text { SD) }\end{array}$ & P-value \\
\hline \multirow{2}{*}{ Age Group } & - $<40$ years & $9.6 \pm 3.3$ & \multirow{2}{*}{$0.119^{*}$} \\
\hline & - $\geq 40$ years & $10.2 \pm 3.9$ & \\
\hline \multirow{2}{*}{ Sex } & - Male & $9.6 \pm 2.9$ & \multirow{2}{*}{$0.327^{*}$} \\
\hline & - Female & $9.9 \pm 3.8$ & \\
\hline \multirow{2}{*}{ Nationality } & - Saudi & $9.8 \pm 3.5$ & \multirow{2}{*}{$0.215^{*}$} \\
\hline & - Non-Saudi & $10.5 \pm 3.1$ & \\
\hline \multirow{3}{*}{ Educational Level } & - Illiterate & $9.5 \pm 3.2$ & \multirow{3}{*}{$0.063 * *$} \\
\hline & - Low & $10.1 \pm 3.4$ & \\
\hline & - High & $10.4 \pm 4.8$ & \\
\hline \multirow{2}{*}{ Marital Status } & - Married & $9.4 \pm 3.7$ & \multirow{2}{*}{$0.049 *$} \\
\hline & - Single & $10.2 \pm 3.3$ & \\
\hline \multirow{2}{*}{ Occupational Status } & - Employed & $9.9 \pm 3.3$ & \multirow{2}{*}{$0.175^{*}$} \\
\hline & - Unemployed & $9.7 \pm 3.7$ & \\
\hline \multirow{2}{*}{ Family Income/month } & - $<10,000$ & $9.7 \pm 3.4$ & \multirow{2}{*}{$0.059^{*}$} \\
\hline & - $\geq 10,000$ & $10.1 \pm 3.5$ & \\
\hline \multirow{2}{*}{ Skin Colour } & - Dark & $10.4 \pm 3.1$ & \multirow{2}{*}{$<0.001 *$} \\
\hline & - Fair & $8.5 \pm 2.9$ & \\
\hline
\end{tabular}

*Student t-test used to compare the mean difference between the two groups.

*ANOVA test used to compare the mean difference between groups.

Simple linear regression revealed that the level of awareness about skin cancer could be predicted from the educational level (accounted for $9.2 \%$ of the variation) and skin color (accounted for $26.8 \%$ of the variation) of the respondents. For every degree increase in the educational level, the level of awareness increased by 0.469 points on the scale, "95\% confidence interval limits for the slope were $[0.09,1.07] "$. Likewise, the level of awareness of participants with fair colored skin decreased by 1.825 points on the scale, "95\% confidence interval limits for the slope were $[-2.63,-1.02] "$.

The results of the multiple regression analysis revealed that; when the level of awareness about skin cancer was predicted it was found that the age (Beta $=0.03, \mathrm{p}=0.047$ ), educational level (Beta $=0.63, \mathrm{p}=0.042$ ) and skin color $($ Beta $=-2.14, \mathrm{p}<0.001)$ were significant predictors. The overall model fit was $\mathrm{R}^{2}=0.294$.

Accordingly, for every year increase in the respondent's age, the awareness score increased by 0.03 points, "95\% CI $[0.003,0.061] "$. In addition, a level increase in the participants' education was associated with an increase in the awareness score by 0.63 points, "95\% CI [0.03, 1.225]". Likewise, the level of awareness of participants with fair colored skin decreased by 2.14 points on the scale, "95\% CI [-2.95, -1.32]". 
Table 5. Associations between Awareness score and covariates (linear regression)

\begin{tabular}{|c|c|c|c|}
\hline Covariate & B Coefficient & 95\% Confidence Interval & P-value \\
\hline \multicolumn{4}{|c|}{ Simple Linear Regression Analysis } \\
\hline - Age in years & 0.028 & $0.003 \_0.059$ & 0.077 \\
\hline - Sex & 0.358 & $-0.415 \_1.131$ & 0.363 \\
\hline - Nationality & 0.721 & $-0.523 \_1.966$ & 0.255 \\
\hline - Educational Level & 0.469 & $0.093 \_1.069$ & 0.042 \\
\hline - Marital Status & 0.674 & $-0.074 \_1.422$ & 0.073 \\
\hline - Occupational Status & 0.061 & $-0.678 \_0.808$ & 0.873 \\
\hline - Family Income/month & 0.190 & $-0.220 \_0.600$ & 0.362 \\
\hline - Skin Colour & -1.825 & $-2.627-1.023$ & $<0.001$ \\
\hline \multicolumn{4}{|c|}{ Multivariate Linear Regression Analysis } \\
\hline - Intercept & 12.410 & $10.486 \_14.335$ & $<\mathbf{0 . 0 0 1}$ \\
\hline - Age in years & 0.031 & $0.003 \_0.061$ & 0.047 \\
\hline - Educational Level & 0.628 & $0.030 \_1.225$ & 0.042 \\
\hline - Skin Colour & -2.135 & $-2.948 \_-1.321$ & $<0.001$ \\
\hline
\end{tabular}

\section{Discussion}

It has been reported that the incidence of skin cancer had increased more than all other cancers combined over the past three decades (Stern, 2010). About half of the Americans who lived to age 65 will have either Basal Cell Carcinoma (BCC) or Squamous Cell Carcinoma (SCC) at least once in their lifetime (National Cancer Institute, 2009/2010). The recent official Cancer Incidence reported from Saudi Arabia indicates that skin cancer ranked the ninth most common cancer for both sexes. The highest females ASR of non-melanomatus skin cancer was (5.8/100000) in Jazan while the highest males ASR was (4.6/100000) in Riyadh (Haya, 2014).

Skin cancers are preventable, and the great majority of them were attributed to sun exposure (Koh \& Geller, 2004). Therefore, knowledge, attitude and practice level of individuals toward the disease are important factors in the control and early detection. This cross-sectional study was carried out to assess the level of knowledge, attitudes and behaviors of people $(n=431)$ in Riyadh city towards skin cancer. The majority of participants were women $(63 \%)$ with a mean age of 35 years. In the current study (71\%) were self-reported dark skin while in the Avagyan project and Argyriadou et al. (2005) the majority reported fair skin.

In the current work, it has been noted that the study respondents have limited knowledge about skin cancer which was similar to the findings of a study using representative telephone survey technique and was conducted by the American Academy of Dermatology (ADD) in 1995.

Moreover, the study found lower levels of awareness about the risk factors for skin cancer compared to Miles et al. (2005). The majority of participants $83.4 \%$ did not know that sun exposure is a risk for skin cancer, and $84.2 \%$ consider suntan as a sign for healthy skin. However, Avagyan reported that, most of the population correctly identified that the sun causes skin cancer and that it is more harmful for their type of skin (Avagyan, 2009).

Further, more than two thirds of the participants knew the times of day when the sun is the most dangerous for their skin, which is similar to the results of Avagyan (Avagyan, 2009). Moreover, only 31.4\% mentioned severe childhood sunburn as a risk factor for melanoma compared with the $82 \%$ reported by Miles et al (Miles et al., 2005 ) and $58 \%$ in the US survey (Centers for Disease Control Prevention, 1996). Also, only $42.5 \%$ knew that, having large number of skin moles is an important risk factor for developing melanoma while Miles et al (Miles et al., 2005) reported double this percentage. Lower levels of specific knowledge among participants can be explained by the low relevant public health awareness campaigns for skin cancer in addition to low incidence of skin cancer in darker skinned population.

Attitudes about sun exposure revealed preferences for tanning, as $62 \%$ of the population reported that a suntan makes them look healthier. These results were in consistent with the results of Avagyan (Avagyan, 2009) and the 
British study (Miles et al., 2005) where 50\% of the sample reported that they felt healthier after suntan. Only $25 \%$ felt attractive after a suntan, which was lower than that reported by both Miles et al. (2005) and Avagyan (2009). Statistically significant associations were detected between awareness about skin cancer and age (Beta $=$ $0.03, \mathrm{p}=0.047)$, educational level (Beta $=0.63, \mathrm{p}=0.042)$ and skin color (Beta $=-2.14, \mathrm{p}<0.001)$. These findings were consistent with findings of three studies (Avagyan,G. 2009; Kristjansson, Ullen, \& Helgason, 2004; Nursan Dede Cinar, 2009). This is the first study to examination KAP about skin cancer in Riyadh, Saudi Arabia and the findings cannot be generalized to the whole KSA population as a whole.

\section{Conclusions}

To our knowledge, this is the first KAP study about skin cancer prevention in Saudi Arabia. Despite the limitations, the present study's findings suggested that this sample of the Riyadh population lacks the sufficient knowledge to understand and assess the importance of skin cancer risk determinants. In addition, the level of knowledge, attitude and behaviors are influenced by several factors in the current sample: age, education level and skin color. There is an urgent need for changing public beliefs and protective behaviors towards skin cancer. Furthermore, planning future research as well as health education programs should be inaugurated.

\section{References:}

American Cancer Society. (2013). Skin Cancer Facts. Retrieved from $\mathrm{http} / / / \mathrm{www} . c a n c e r . o r g /$ cancer/cancercauses/sunanduvexposure/skin-cancer-facts

Aquilina, S., Gauci, A. A., Ellul, M., \& Scerri, L. (2004). Sun awareness in Maltese secondary school students. $J$ Eur Acad Dermatol Venereol, 18(6), 670-675. http://dx.doi.org/10.1111/j.1468-3083.2004.01046.x

Argyriadou, S., Makridis, D., Lygidakis, H., Apazidis, G., \& Gagalis, G. (2005). Knowledge and behaviour of tourists towards the sun, as studied in a region of northern Greece. Rural Remote Health, 5(4), 367.

Avagyan, G. (2009). Skin Cancer Knowledge, Attitudes, and Practices Among Residents of Yerevan, Armenia. (master), American University of Armenia College of Health Sciences. Retrieved from http://auachsr.com/PDF/MPH/2009/Avagyan,\%20Gayane.pdf

Bradford, P. T. (2009). Skin cancer in skin of color. Dermatol Nurs, 21(4), 170-177.

Cokkinides, V., Weinstock, M., Glanz, K., Albano, J., Ward, E., \& Thun, M. (2006). Trends in sunburns, sun protection practices, and attitudes toward sun exposure protection and tanning among US adolescents, 1998-2004. Pediatrics, 118(3), 853-864. http://dx.doi.org/10.1542/peds.2005-3109

Geller, A. C., Shamban, J., O'Riordan, D. L., Slygh, C., Kinney, J. P., \& Rosenberg, S. (2005). Raising sun protection and early detection awareness among Florida high schoolers. Pediatr Dermatol, 22(2), 112-118. http://dx.doi.org/10.1111/j.1525-1470.2005.22204.x

Harrison, S. L., Saunders, V., \& Nowak, M. (2007). Baseline survey of sun-protection knowledge, practices and policy in early childhood settings in Queensland, Australia. Health Educ Res, 22(2), 261-271. http://dx.doi.org/10.1093/her/cyl068

Haya, A. (2014). Cancer Incidence Report, Saudi Arabia 2010. (vol. 14, p.103). kingdom of Saudi Arabia: Ministry of Health, Saudi cancer registry 2014 .

National Cancer Institute. (2009/2010). Sun Protection. Cancer Trends Progress Report - 2009/2010 Update. National Cancer Institute. Retrieved from http://progressreport.cancer.gov/doc_detail.asp?pid=1\&did= $2007 \&$ chid $=71 \&$ coid $=711 \&$ mid

Jones, B., Oh, C., Corkery, E., Hanley, R., \& Egan, C. A. (2007). Attitudes and perceptions regarding skin cancer and sun protection behaviour in an Irish population. $J$ Eur Acad Dermatol Venereol, 21(8), 1097-1101. http://dx.doi.org/10.1111/j.1468-3083.2007.02209.x

Koh, H. K., \& Geller, A. C. (2004). Skin cancer prevention comes of age. Am J Prev Med, 27(5), 484-485. http://dx.doi.org/10.1016/j.amepre.2004.08.011

Kristjansson, S., Ullen, H., \& Helgason, A. R. (2004). The importance of assessing the readiness to change sun-protection behaviours: a population-based study. Eur $J$ Cancer, 40(18), 2773-2780. http://dx.doi.org/10.1016/j.ejca.2004.08.027

Leiter, U., Eigentler, T., \& Garbe, C. (2014). Epidemiology of skin cancer. Adv Exp Med Biol, 810, 120-140.

Leiter, U., \& Garbe, C. (2008). Epidemiology of melanoma and nonmelanoma skin cancer--the role of sunlight. Adv Exp Med Biol, 624, 89-103. http://dx.doi.org/10.1007/978-0-387-77574-6_8 
Lucas R, M. T., Smith, W., \& Armstrong B. (2006). Solar Ultraviolet Radiation: Global Burden of Disease from Solar Ultraviolet Radiation. EnvironmentalBurden of Disease Series, No. 13. 2006. Geneva: World Health Organization.

Miles, A., Waller, J., Hiom, S., \& Swanston, D. (2005). SunSmart? Skin cancer knowledge and preventive behaviour in a British population representative sample. Health Educ Res, 20(5), 579-585. http://dx.doi.org/10.1093/her/cyh010

Nursan Dede Cinar, S. C., Ayse Karakoc, Fatma Ucar. (2009). Knowledge, Attitudes and Behaviors Concerning Sun Protection/Skin Cancer Among Adults in Tyrkey. Pak J Med Sci, 25 (1), 108-112.

Nyiri, P. (2005). Sun protection in Singapore's schools. Singapore Med J, 46(9), 471-475.

Worled Health Organisation. Skin cancers. Retrieved April 16, 2015, from http://www.who.int/uv/faq/skincancer/en/index 1.html

Centers for Disease Control Prevention. (1996). Survey of knowledge of and awareness about melanoma--United States, 1995. MMWR Morb Mortal Wkly Rep, 45(17), 346-349.

Rigel, D. S., Friedman, R. J., Dzubow, L.M., et al. ( 2004). Cancer of the Skin. Philadelphia, Pa, WB Saunders Co. (pp. 29-45).

Stern, R. S. (2010). Prevalence of a history of skin cancer in 2007: results of an incidence-based model. Arch Dermatol, 146(3), 279-282. http://dx.doi.org/10.1001/archdermatol.2010.4

Xiang, F., Lucas, R., Hales, S., \& Neale, R. (2014). Incidence of nonmelanoma skin cancer in relation to ambient UV radiation in white populations, 1978-2012: empirical relationships. JAMA Dermatol, 150(10), 1063-1071. http://dx.doi.org/10.1001/jamadermatol.2014.762

\section{Copyrights}

Copyright for this article is retained by the author(s), with first publication rights granted to the journal.

This is an open-access article distributed under the terms and conditions of the Creative Commons Attribution license (http://creativecommons.org/licenses/by/3.0/). 